\title{
ARTICLE Comparison of biological effects of modulated electro-hyperthermia and conventional heat treatment in human lymphoma U937 cells
}

\author{
G Andocs ${ }^{1,4}$, MU Rehman ${ }^{1,4}$, Q-L Zhao ${ }^{1}$, Y Tabuchi ${ }^{2}$, M Kanamori $^{3}$ and T Kondo ${ }^{1}$
}

Loco-regional hyperthermia treatment has long history in oncology. Modulated electro-hyperthermia (mEHT, trade name: oncothermia) is an emerging curative treatment method in this field due to its highly selective actions. The impedance-matched, capacitive-coupled modulated radiofrequency (RF) current is selectively focused in the malignant cell membrane of the cancer cells. Our objective is studying the cell-death process and comparing the cellular effects of conventional water-bath hyperthermia treatment to mEHT. The U937 human histiocytic lymphoma cell line was used for the experiments. In the case of conventional hyperthermia treatment, cells were immersed in a thermoregulated water bath, whereas in the case of mEHT, the cells were treated using a special RF generator (LabEHY, Oncotherm) and an applicator. The heating dynamics, the maximum temperature reached $\left(42{ }^{\circ} \mathrm{C}\right)$ and the treatment duration $(30 \mathrm{~min})$ were exactly the same in both cases. Cell samples were analysed using different flow cytometric methods as well as microarray gene expression assay and western blot analysis was also used to reveal the molecular basis of the induced effects. Definite difference was observed in the biological response to different heat treatments. At $42^{\circ} \mathrm{C}$, only $\mathrm{mEHT}$ induced significant apoptotic cell death. The GeneChip analysis revealed a whole cluster of genes, which are highly up-regulated in case of only RF heating, but not in conventional heating. The Fas, c-Jun N-terminal kinases (JNK) and ERK signalling pathway was the dominant factor to induce apoptotic cell death in $\mathrm{mEHT}$, whereas the cell-protective mechanisms dominated in case of conventional heating. This study has clearly shown that conventional hyperthermia and RF mEHT can result in different biological responses at the same temperature. The reason for the difference is the distinct, non-homogenous energy distribution on the cell membrane, which activates cell death-related signalling pathways in $\mathrm{mEHT}$ treatment but not in conventional heat treatment.

Cell Death Discovery (2016) 2, 16039; doi:10.1038/cddiscovery.2016.39; published online 13 June 2016

\section{INTRODUCTION}

What is modulated electro-hyperthermia (mEHT)?

mEHT (trade name: oncothermia) is an electromagnetic heat treatment method, a non-invasive cellular selective oncotherapy, using the capacitive-coupled energy of $13.56 \mathrm{MHz}$ radiofrequency (RF) to destroy the malignant cells. It was introduced into the human oncological treatment practice more than 20 years ago, and since then its therapeutic benefits have been proven in many different areas of clinical oncology. ${ }^{1-5}$ In parallel with the clinical application, intensive basic research has been performed to get a better understanding of the underlying cellular and molecular biology effects of the RF-field interaction with living tissue. ${ }^{6,7}$ In previous in vivo studies, it was observed that $\mathrm{MEHT}$ treatment can induce massive programmed cell death in the treated tumour, ${ }^{8}$ and this apoptotic cell death process has some unique immunological aspects, ${ }^{9}$ which can open up possible new immunotherapeutic combination modalities. ${ }^{10,11}$

\section{Theoretical background}

In one of our previous investigations, a comparative in vivo study was performed to reveal the difference in the biological response between conventional heat treatment and mEHT. ${ }^{12}$ In this experiment, the RF heating induced much more significant tumour tissue distraction, even in a physiological temperature range, than conventional heat treatment. This unique characteristic of the RF heating was realised many decades ago by different workgroups; however, the exact explanation of this effect is still missing. There are several theoretical considerations about the existence of a special non-thermal effect of the RF field, ${ }^{13-15}$ but these remain controversial, ${ }^{16}$ and still lack unequivocal experimental evidence and a widely accepted explanation of its mechanism of action. ${ }^{17}$

Another interesting approach to explain the special nature of the biological effect of the RF field is the so-called microthermal concept. This hypothesis was first introduced by Lebovitz, ${ }^{18}$ and since then many research groups have proved that RF exposure of biological material (cells) would induce a highly non-homogenous energy distribution on the cell membrane. ${ }^{19-21}$ Unfortunately, these models and studies did not take into considerations, which was achieved in the past few years in connection with the fine microstructure of the cell membrane.

The classic fluid mosaic membrane model ${ }^{22}$ became outdated after recent research results had been revealed that the cell

\footnotetext{
${ }^{1}$ Department of Radiological Sciences, Graduate School of Medicine and Pharmaceutical Sciences, University of Toyama, Toyama, Japan; ${ }^{2}$ Division of Molecular Genetics, Life

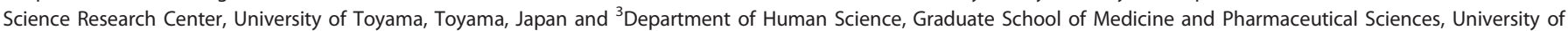
Toyama, Toyama, Japan.

Correspondence: G Andocs (gandocs@gmail.com)

${ }^{4}$ These authors contributed equally to this work.

Received 11 April 2016; revised 28 April 2016; accepted 1 May 2016; Edited by A Rufini
} 
membrane has a highly organised microstructure, comprising special microdomains of the membrane, called membrane rafts. ${ }^{23,24}$ According to Pike: 'Lipid rafts are small (10-200 nm), heterogeneous, highly dynamic, sterol- and sphingolipid-enriched domains that compartmentalise cellular processes. Small rafts can sometimes be stabilised to form larger platforms through proteinprotein and protein-lipid interactions'. ${ }^{25}$ A variety of proteins, especially those involved in cell signalling, have been shown to partition into lipid rafts. As a result, lipid rafts are thought to be involved in the regulation of signal transduction. ${ }^{26}$ Although rafts have a distinctive protein and lipid composition, it is obvious that its electromagnetic parameters (dielectric constant, permittivity, conductivity, etc.) differ from the other part of the cell membrane.

According to our knowledge, our workgroup studied the biological effect of the RF field for the first time, taking into consideration the lipid raft membrane model, ${ }^{27}$ developed a wellelaborated theoretical framework of capacitive-coupled RF field interaction with cell membrane microdomains, ${ }^{28}$ and performed a computer simulation and in vitro experiments to prove the hypothesis. ${ }^{29}$ The theory is described in detail elsewhere, ${ }^{30}$ but very briefly below see Figure 1.

The capacitive-coupled RF current at $13.56 \mathrm{MHz}$ frequency and in the applied field strength $(<500 \mathrm{~V} / \mathrm{m})$ cannot penetrate into the cell interior, because the cell membrane is an excellent electric insulator. $^{31}$ The energy of the amplitude-modulated RF current is absorbed by the extracellular matrix, $^{32}$ and mostly the cell membrane by beta-dispersion of the plasma membrane. ${ }^{33}$ The membrane rafts, according to their different electromagnetic properties, absorb more RF power than the other lipid bilayer part of the cell membrane. The higher current density and dielectric loss of the membrane rafts was proven by special software simulation. ${ }^{34}$ The higher energy absorption means higher local temperature of the raft microdomain during continuous RF current delivery to the cell.

The purpose of the study. In our previous investigations, we found that $\mathrm{mEHT}$ treatment can induce the same biological response (apoptotic cell death) in U937 cell line at $3{ }^{\circ} \mathrm{C}$ lower than conventional water bath hyperthermia (WHT) treatment. $^{29}$ According to previous reports from different workgroups, $42^{\circ} \mathrm{C}$ heat treatment for $30 \mathrm{~min}$ induced no cell damage in this cell line. ${ }^{35-38}$ In the present study, we compared the biological effect of mEHT treatment and conventional WHT treatment in the U937 cell line at $42{ }^{\circ} \mathrm{C}$, and investigated the underlying molecular mechanism of the induced-biological response.

\section{RESULTS}

mEHT-induced apoptosis

The morphological changes evident of apoptosis were detected using bright field microscopy imaging in fixed and Giemsa stained cell samples (Figure 2a) showed that the typical morphological changes associated with apoptosis were more prominent in the mEHT-treated cells than in WHT-treated cell samples. To further confirm the apoptosis induction after $3 \mathrm{~h}$ of treatment, cells were subjected to the DNA fragmentation assay. It was found that the $\mathrm{mEHT}$ treatment showed significant enhancement of DNA fragmentation percentage compared to WHT treatment (Figure 2c), whereas WHT did not induce an increase in DNA fragmentation percentage.

Further, to distinguish between early and late phase apoptosis (secondary necrosis), cells were subjected to Annexin V-FITC/PI double staining. Flow cytometry analysis revealed that $\mathrm{mEHT}$ treatment significantly enhanced the percentage of early apoptotic (Annexin V-FITC) cells (apoptotic percentage), compared with treatment WHT alone (Figure $2 \mathrm{~b}$ ).

$\mathrm{mEHT}$-induced loss of mitochondrial membrane potential (MMP) To assess the role of mitochondrial function in the mEHT-induced apoptosis, its effect on MMP was evaluated. The fraction of cells with low MMP significantly increased in the mEHT treatment compared to either control or WHT alone (Figure 3a).

Effects of mEHT on intracellular $\left[\mathrm{Ca}^{2+}\right]_{\mathrm{i}}$

As U937 cells have been known to possess a $\left[\mathrm{Ca}^{2+}\right]_{\mathrm{i}}$ dependent apoptosis pathway, their role in mEHT-induced apoptosis was investigated. Cells were treated with mEHT and WHT; after $3 \mathrm{~h}$ of incubation, changes in the $\left[\mathrm{Ca}^{2+}\right]_{\mathrm{i}}$ were detected by flow cytometry using Fluo-3-AM dye. The mEHT treatment significantly

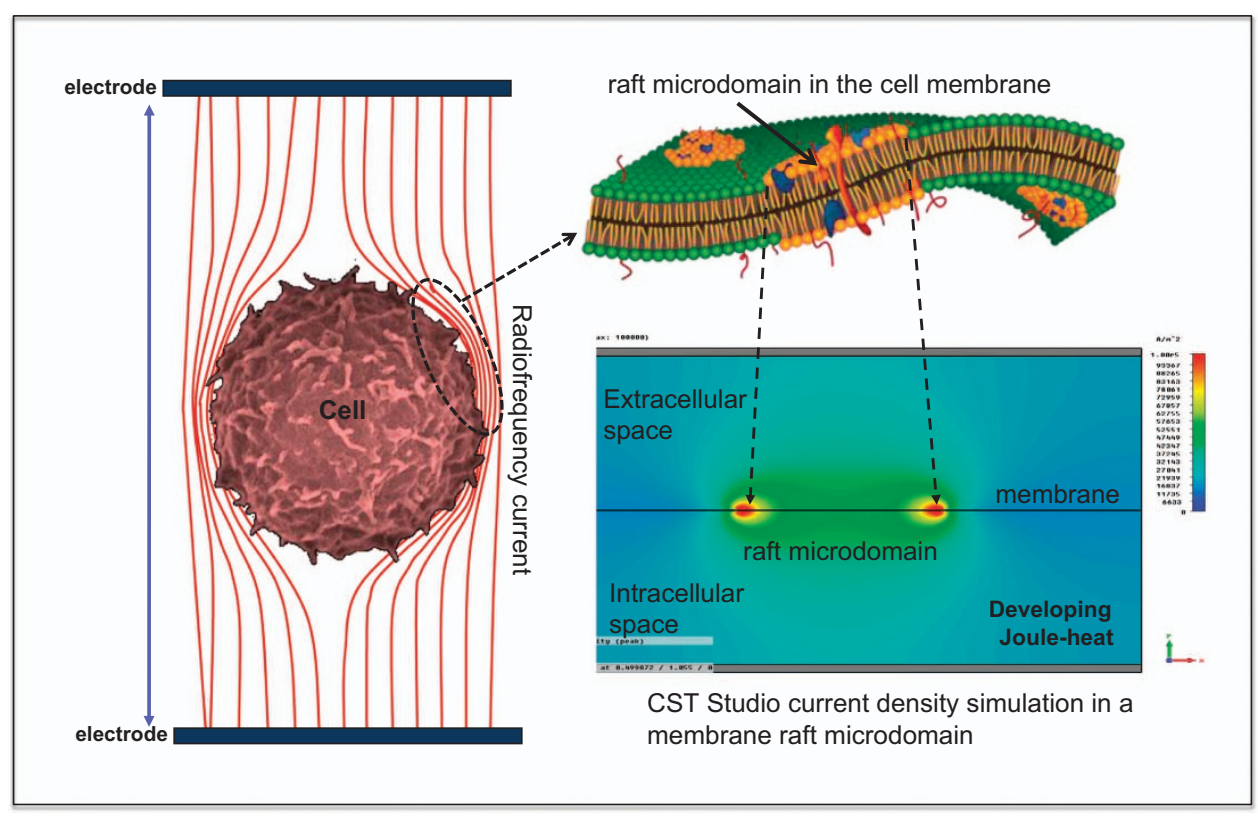

Figure 1. Schematic representation of the membrane raft-specific, localised heat stress. 
a

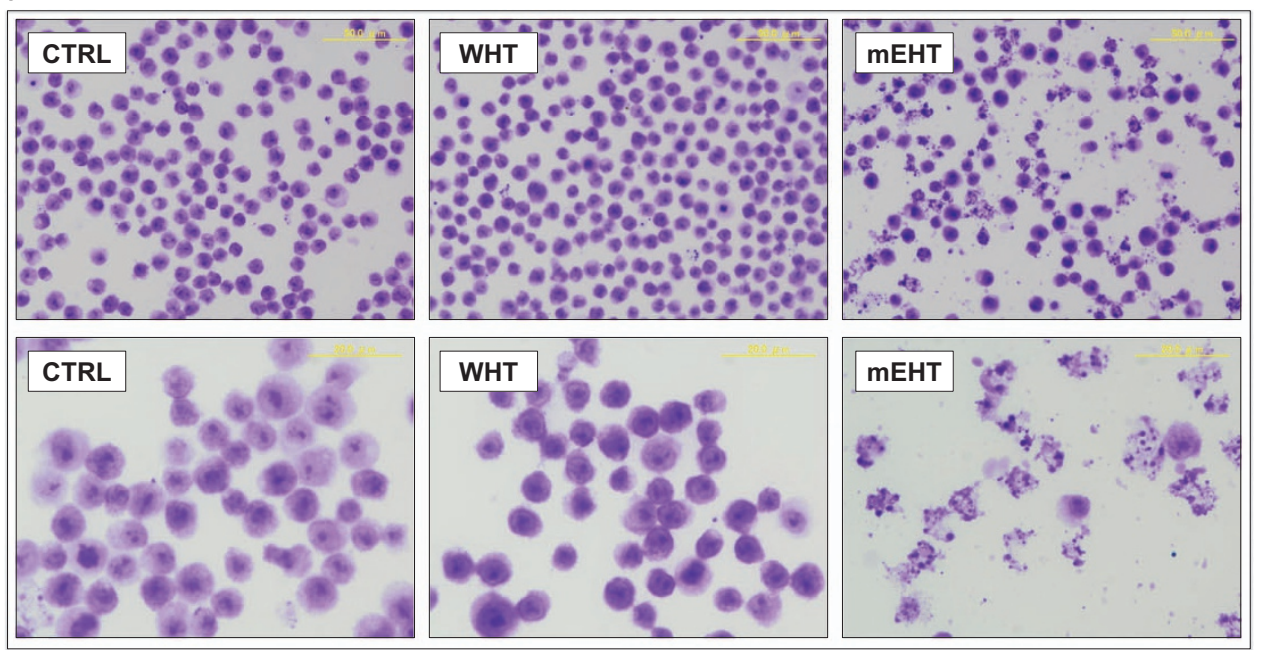

b
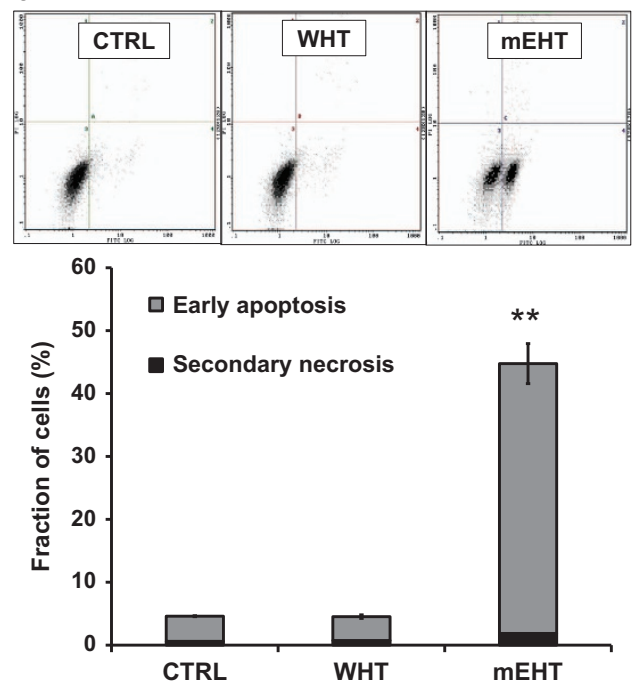

C

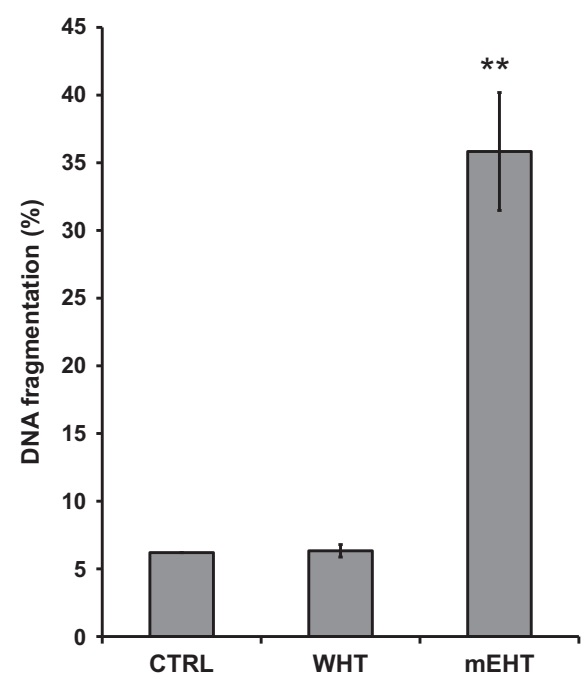

Figure 2. Representative microscopy images of untreated control, WHT-treated and mEHT-treated cells, $3 \mathrm{~h}$ post-treatment in Giemsa stained cell samples (a). Representative flow cytometric histogram of the Annexin V-FITC and PI staining $3 \mathrm{~h}$ after treatment. The quantitative analysis shows a significant increase of Annexin V positive-cell fraction only in $\mathrm{mEHT}$ samples (b). Quantitative results from DNA fragmentation assay. The mEHT-treated cells showed a significant increase in DNA fragmentation percentage, which is one of the hallmarks of apoptotic cell death (c). The results are presented as the mean \pm S.D. $(n=3)$. ${ }^{* * P}<0.01$ as compared to WHT treatment.

increased the $\left[\mathrm{Ca}^{2+}\right]_{i}$ concentration, whereas no such change was observed in WHT treatment alone (Figure 3b).

Effects of mEHT on the MAPK pathway

In order to investigate the effects of mEHT treatment on the MAPK pathway, western blot (WB) analysis was performed at 1 and $3 \mathrm{~h}$ after mEHT and WHT treatment. The results showed that the phosphorylation of JNK was markedly increased following mEHT treatment at 1 and $3 \mathrm{~h}$. Similarly, at $1 \mathrm{~h}$ phosphorylation of ERK was also more increased with $\mathrm{MEHT}$ treatment than the WHT treatment. However, no significant change was observed in the full form of JNK and ERK with both treatments (Figure 4).

FAS externalisation and caspase- 8 activation induced by mEHT treatment

The Fas receptor is a death receptor on the surface of cells that leads to one of the apoptotic pathways, the extrinsic pathway, through death-inducing signalling complex (DISC) assembly and subsequent caspase- 8 activation. To determine the involvement of the extrinsic apoptotic pathway, the effects of mEHT treatment on Fas externalisation and caspase- 8 activation were studied. The protein expression of Fas was markedly increased $3 \mathrm{~h}$ after $\mathrm{mEHT}$ treatment compared to treatment with WHT alone. Simultaneously, increased cleaved caspase- 8 was observed after 1 and $3 \mathrm{~h}$ following $\mathrm{mEHT}$ treatment than the WHT treatment (Figure 5).

Expression of apoptosis-related proteins

$\mathrm{Bcl}-2$ family proteins with anti- or pro-apoptotic functions have a pivotal role in apoptosis by releasing cytochrome-c from the mitochondria, to activate the caspase cascade. To investigate the involvement of $\mathrm{Bcl}-2$ family proteins in the mEHT treatmentinduced apoptosis, WB analysis was undertaken. Increased expression of pro-apoptotic Bcl-2 family protein, truncated Bid (t-Bid, an active form of Bid) was observed following mEHT treatment. However, activation of Bid with WHT was not observed (Figure $6 \mathrm{a})$, and the expression of pro-apoptotic Bax and antiapoptotic Bcl-XL remain unchanged (Figure $6 \mathrm{~b}$ ).

As caspases are considered the main executioner of apoptosis, the effect of mEHT treatment on caspase-3 was evaluated. 

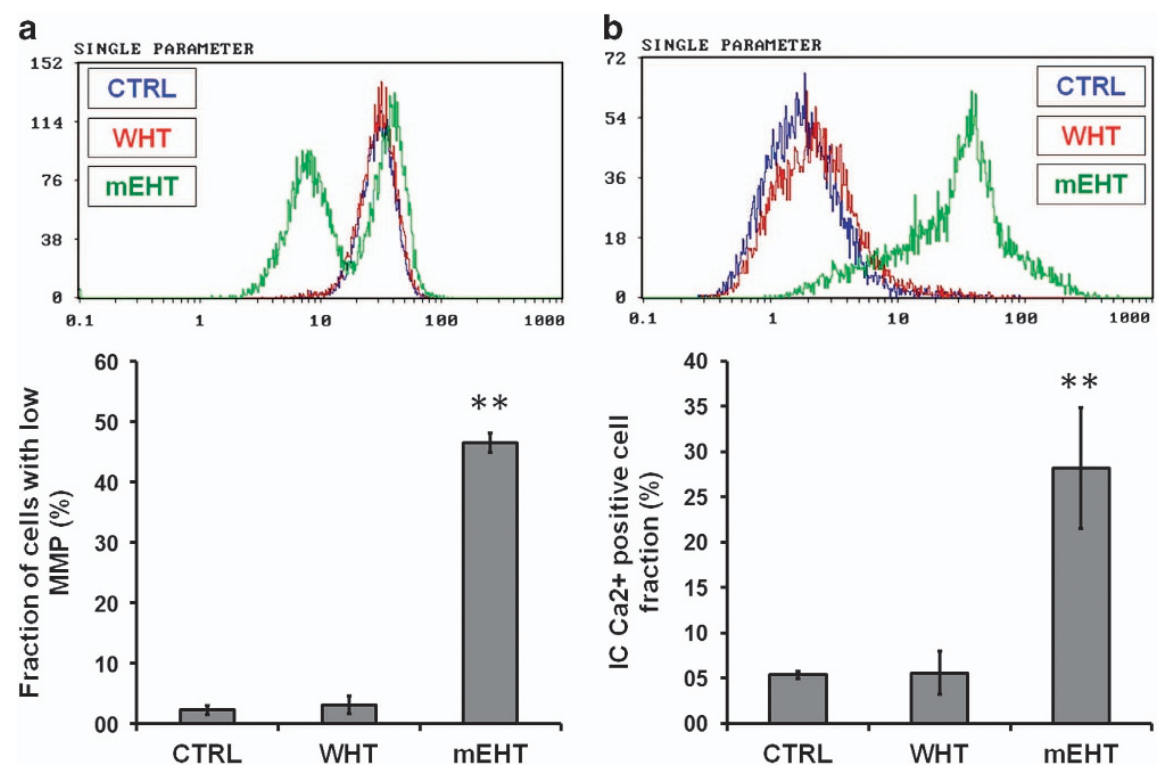

Figure 3. Representative flow cytometric histogram of the MMP. The quantitative analysis revealed a significantly higher number of cells with low MMP in mEHT-treated cells (a). Representative flow cytometric histogram of the intracellular $\mathrm{Ca}^{2+}$ measurement. The quantitative analysis revealed significantly higher intracellular $\mathrm{Ca}^{2+}$ level in mEHT-treated cells (b). The results are presented as the mean \pm S.D. $(n=3)$. ${ }^{* * P}<0.01$ as compared to WHT treatment.

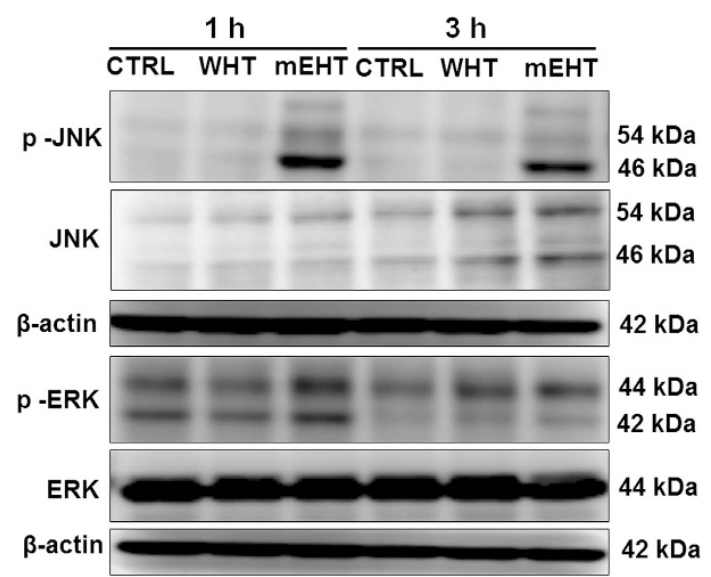

Figure 4. Expression of $\mathrm{p}-\mathrm{JNK}$ was increased at 1 and $3 \mathrm{~h}$, similarly p-ERK was also increased at $1 \mathrm{~h}$ following mEHT treatment as evidenced by the WB analysis.

The active form of caspase-3 (cleaved capase-3) was markedly increased with $\mathrm{mEHT}$, whereas no increase was observed with WHT (Figure 6c).

\section{Gene chip analysis}

To identify the biological functions and gene networks regulated by $\mathrm{mEHT}$ treatment, we carried out gene-expression profiling coupled to functional and signalling characterisation by the Ingenuity software Inc. (Mountain View, CA, USA). Global-scale gene expression analysis of cells treated with $\mathrm{mEHT}$ identified a whole cluster of genes that were up-regulated by a factor of 2 or greater (Figure 7a). In addition, functional category and gene network analyses were conducted by use of the Ingenuity Pathways Knowledge Base (Ingenuity Systems Inc., Mountain View, CA, USA). According to the careful analysis, two markedly different activated gene networks were identified (Figures $7 \mathrm{a}$ and b) in mEHT and WHT samples, respectively. In gene network A,

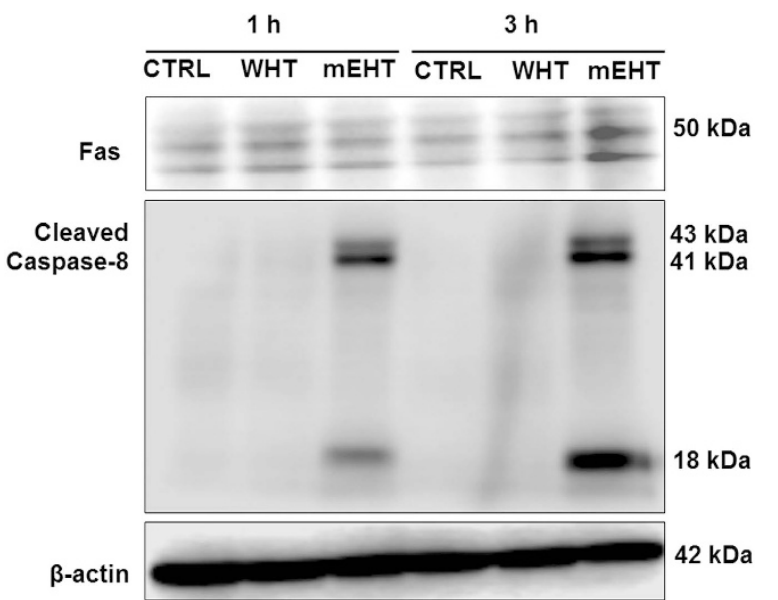

Figure 5. Western blot analysis revealed increased FAS expression at $3 \mathrm{~h}$; subsequently the expression of cleaved caspase-8 was also markedly increased at $3 \mathrm{~h}$ following mEHT treatment.

containing the up-regulated genes in mEHT-treated cells, this was mainly associated with the molecular function of cell death (EGR1, JUN, and CDKN1A). In WHT-treated cells, however, this cell-death related gene network remained silent. In gene network $B$ containing the up-regulated genes in WHT-treated cells, several HSPs, such as Hsp105 (HSPH1), Hsp90A (HSP90AA1) were observed. This cytoprotective gene network $B$ remained silent in $\mathrm{mEHT}$-treated cells. The ingenuity pathway analysis predicted ERK activation and the relationship between JUN and ERK in OTMtreated cells. This activation mechanism is missing in the case of WHT-treated cells (Figure 7d).

\section{DISCUSSION}

Our results have clearly demonstrated the significant difference in the biological response of different forms of heat treatments, but at the same temperature in U937 hystiocytic lymphoma cell line. 
a

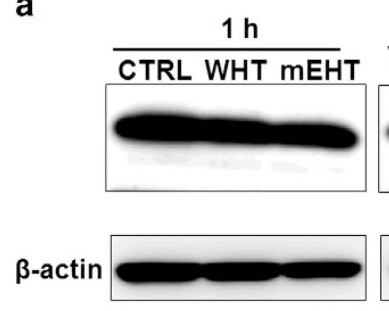

$3 \mathrm{~h}$

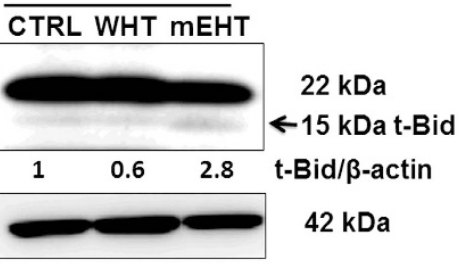

b

C

$1 \mathrm{~h}$

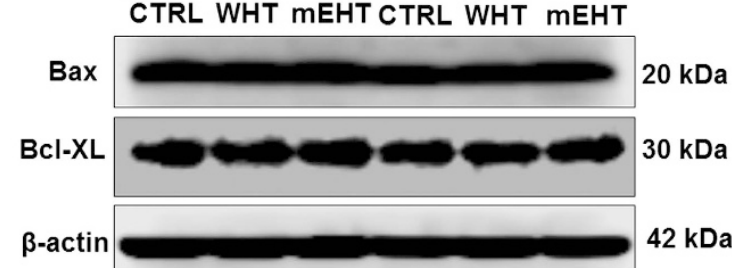

$3 \mathrm{~h}$

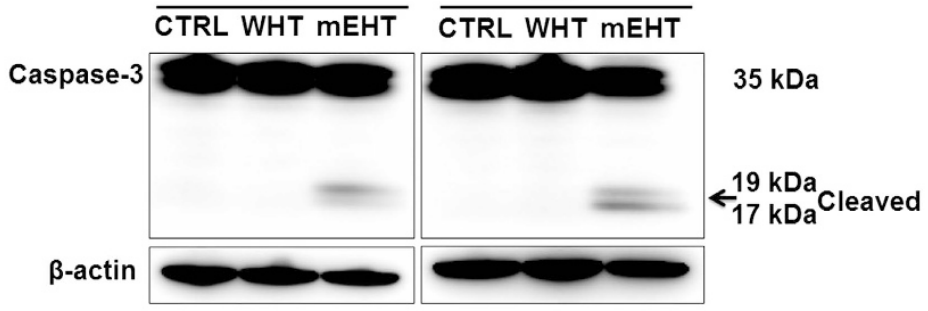

Figure 6. The expression of pro-apoptotic Bcl-2 family protein, truncated Bid (t-Bid, an active form of Bid, indicated by the arrows) was increased following $\mathrm{mEHT}$ treatment at $3 \mathrm{~h}$. The $\mathrm{t}$-Bid signals were normalised to the $\beta$-actin signals, and the relative ratios are shown below each band (a). However, expression of Bax and Bcl-XL remained unchanged (b). The WB analysis clearly showed the increased expression of cleaved caspase-3 in mEHT-treated samples at 1 and $3 \mathrm{~h}$ (c).

mEHT treatment at $42^{\circ} \mathrm{C}$ temperature level induced massive apoptotic cell death, showing the characteristic morphological signs of apoptosis $3 \mathrm{~h}$ post-treatment in Giemsa stained samples. The quantitative analysis also showed a pronounced increase of apoptotic cell fraction in Annexin V-FITC/PI assay. Massive DNA fragmentation was also measured in the mEHT-treated cell samples. None of these signs of cell death were observed in WHT-treated cell samples at $42{ }^{\circ} \mathrm{C}$. This result has a good correspondence with the findings reported in previous papers. ${ }^{35,39}$

But what can be the reason of this huge difference between the two treatments when the temperature level of both treatment methods was the same?

\section{Activation of JNK pathway}

The findings of the WB analysis are in line with the gene chip analysis results. The gene chip analysis predicted the ERK and JNK pro-apoptotic pathway activation in MEHT treatment (Figure 7d), and we have also found a significant p-ERK and p-JNK level elevation in the mEHT-treated samples by the WB analysis. (Figure 4). This pathway was not activated in WHT-treated samples. Previous studies reported that hyperthermia treatment is a strong activator of $\mathrm{JNKs}^{35,39}$ but its activation by heat stress requires a temperature of at least $44^{\circ} \mathrm{C}$. JUN activation was also observed by Furusawa et $a l^{39}$ at $44^{\circ} \mathrm{C}$. It is very interesting that $\mathrm{mEHT}$ treatment-induced the same JNK pathway activation at $42{ }^{\circ} \mathrm{C}$ where conventional heat treatment cannot induce similar changes. This observation supports our theory of the selective membrane raft heating by the applied RF current, because the heat-stressed cell membrane might have been a good activator of the JNK pathway; however, the upstream signalling mechanism is not yet completely understood. ${ }^{40}$ There are some interesting observations, which suppose strong connections between membrane raft-mediated signalling and JNK activation. ${ }^{41,42}$

\section{Activation of cytoprotective gene network in WHT samples}

The gene chip analysis revealed a highly cytoprotective gene network activation in the WHT samples. This network contains upregulated HSP genes, such as Hsp105 or Hsp90A. HSPs (molecular chaperons) have been shown to block apoptosis by interfering with caspase activation and to inhibit apoptosis in a direct or indirect manner. ${ }^{43,44}$ HSPs under the present experimental conditions appeared to behave as anti-apoptosis molecules and prevent any apoptotic cell death in WHT-treated cells. This cytoprotective gene network remained silent in mEHT-treated cells, hence could not block the activated caspase cascade.

Activation of death receptor signalling pathways

We found massive Fas receptor up-regulation in $\mathrm{mEHT}$-treated samples (Figure 5). Fas (CD95 or APO-1) is considered to be the prototypic and major member of the death-receptor family, a subgroup of the TNF receptor superfamily, which also includes the TRAIL receptors TRAIL-R1 (DR4) and TRAIL-R2 (DR5) and can transmit apoptotic signals through the presence of a cytoplasmic death domain. ${ }^{45,46}$ The Fas receptor can be activated by its ligand (FasL). The U937 cells can express FasL, so autocrine Fas-mediated apoptotic cell death mechanism is possible in our case.

However, there is a more interesting possibility for the activation of Fas and other death receptors, which does not require the death receptor ligand.

There are several reports from the past years that death receptors, and especially Fas, are the most abundant transmembrane receptors in the membrane raft domains. ${ }^{47-49} \mathrm{~A}$ growing amount of evidence points to the notion that membrane rafts can serve, in addition to generate a high local concentration of Fas, as platforms for coupling adaptor and effector proteins required for Fas signalling. ${ }^{47,50}$ This is of particular significance in Fas-mediated signal transduction, as the initial signalling events depend on protein-protein interactions. Furthermore, this could facilitate and amplify signalling processes by local assembly of various crossinteracting signalling molecules. ${ }^{51}$

Gajate and Mollinedo and their workgroup made a pioneering work to elucidate the molecular mechanism of membrane raft remodelling in Fas-mediated apoptotic signalling. They stated: 'Modulation of survival and apoptotic signalling routes via rafts could be a promising approach in cancer therapy, and growing evidence shows the potential of rafts as therapeutic targets in cancer therapy. ${ }^{52,53}$ In this regard, the formation of the apoptotic signalling-rich raft clusters named CASMERs ${ }^{50,54}$ favours the onset of apoptosis by bringing together death-promoting receptors and downstream signalling in a rather limited space, thus facilitating 

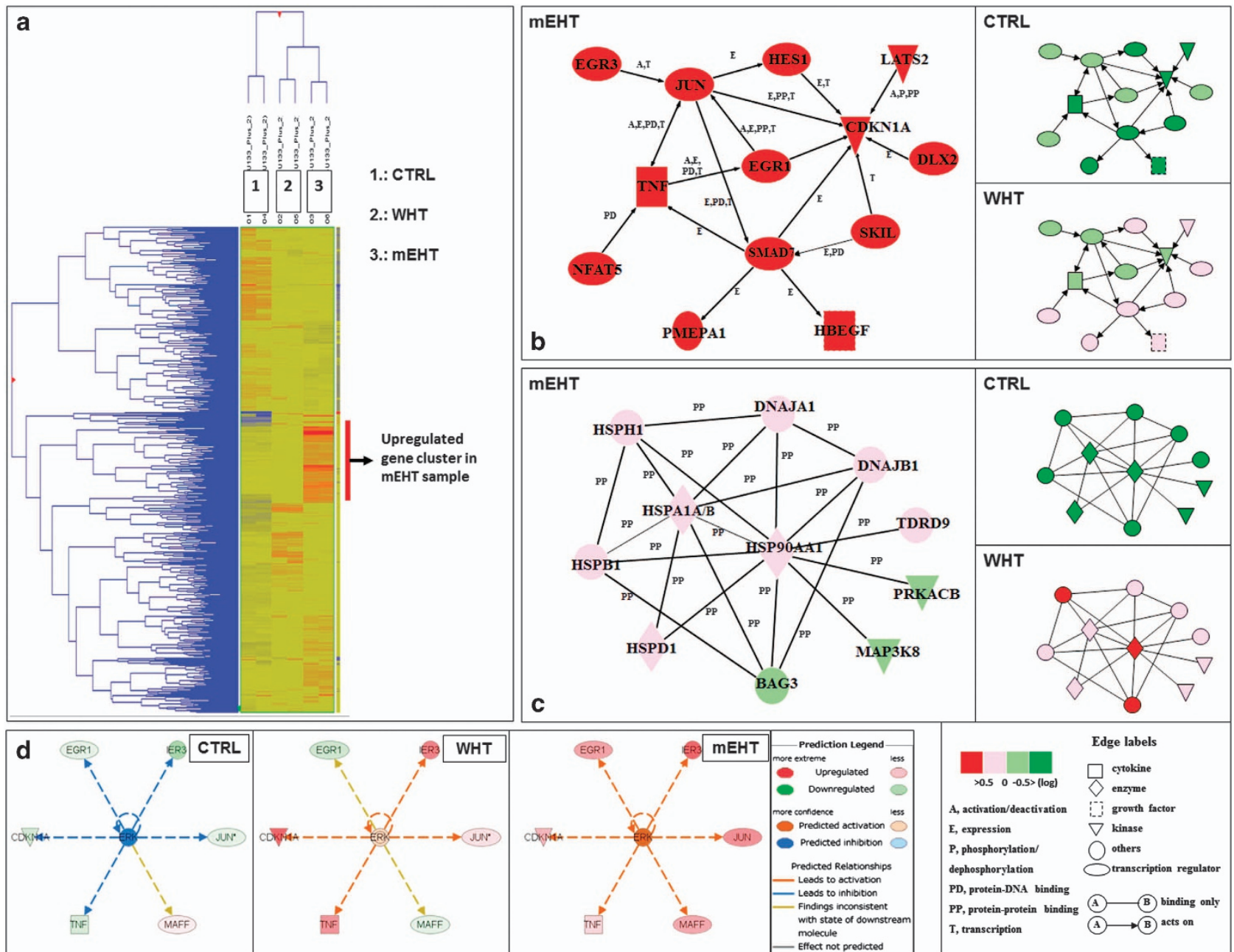

Figure 7. The GeneChip heat map. The analysis revealed a whole cluster of genes, which are highly up-regulated in the case of mEHT-treated samples, but not in WHT (a). The ingenuity pathway analysis clearly demonstrated a specific gene network containing cell death-related genes, such as EGR1, JUN, and CDKN1A. The expression levels of these genes were elevated only in the cells treated with mEHT (b). A specific cytoprotective gene network (heat shock proteins, HSPs) was activated in the case of WHT treatment, but not in mEHT-treated samples (c). The ingenuity pathway analysis predicted ERK activation and the relationship between JUN and ERK in OTM-treated cells. This activation mechanism is missing in the case of WHT-treated cells $(\mathbf{d})$.

protein interactions and the triggering and launching of a potent apoptotic response'. ${ }^{55}$

Alterations in the plasma membrane fluidity and lipid rafts have often been found to be linked during the course of apoptosis. Specific modification of the membrane raft microstructure, especially by increasing fluidity of the membrane and the rafts using different chemical agents (e.g. edelfosine, ${ }^{56}$ cisplatin, ${ }^{57}$ ethanol, ${ }^{58}$ resveratrol ${ }^{59}$ ) result in apoptotic cell death in various experimental conditions in various model systems. ${ }^{60}$

There is also a growing number of evidence that heat shock and certain hyperthermic conditions (i.e. fever) can alter the membrane raft microdomains leading to the activation of death receptors and apoptotic cell death. ${ }^{61-64}$ Heat treatment can also increase the fluidity of the membrane and the raft, initialising different signal transduction pathways including caspase cascade signalling. ${ }^{65}$

According to our theory, alterations of the membrane raft can be done without any specific chemical agent or drug; this can be achieved by biophysical manipulation (specific RF energy deposition and consequent heat stressing) of the membrane rafts of the cancer cells.

On the basis of our initial hypothesis, the membrane raft can absorb more RF energy than the other part of the membrane.
The reason of this increased RF absorption rate is the different electromagnetic properties (electrical conductivity and permittivity) of the membrane raft, due to its different chemical composition, comparing to the simple membrane bilayer. This difference was proven by precise computer simulation. ${ }^{29,34}$ If we accept this theory, our experimental findings can be explained in a simple way (Figure 8).

The increased RF energy absorption of the membrane raft heated it up, resulting in localised heat stress. The heat on the membrane raft increased its fluidity and similarly to heat treatments modified and remodelled the membrane raft microstructure, activating the death receptor Fas signalling pathway. Activation of Fas leads to the recruitment of the adaptor molecule Fas-associated death domain protein and procaspase-8, forming the so-called DISC, ${ }^{66}$ containing Fas, Fas-associated death domain and procaspase- 8 molecules. Fas aggregation and DISC formation result procaspase- 8 transactivation that releases the active caspase-8, thus initiating apoptosis through a subsequent caspase cascade, activating the effector caspases (caspase-3). ${ }^{67,68}$ Furthermore, Fas can also trigger the intrinsic (mitochondrial) apoptotic cell death pathway through cleavage of $\mathrm{BH} 3$-interacting domain death agonist (Bid) into truncated-Bid (t-Bid). ${ }^{69-72}$ Consistent with this, we found that the mEHT-treated samples showed caspase 


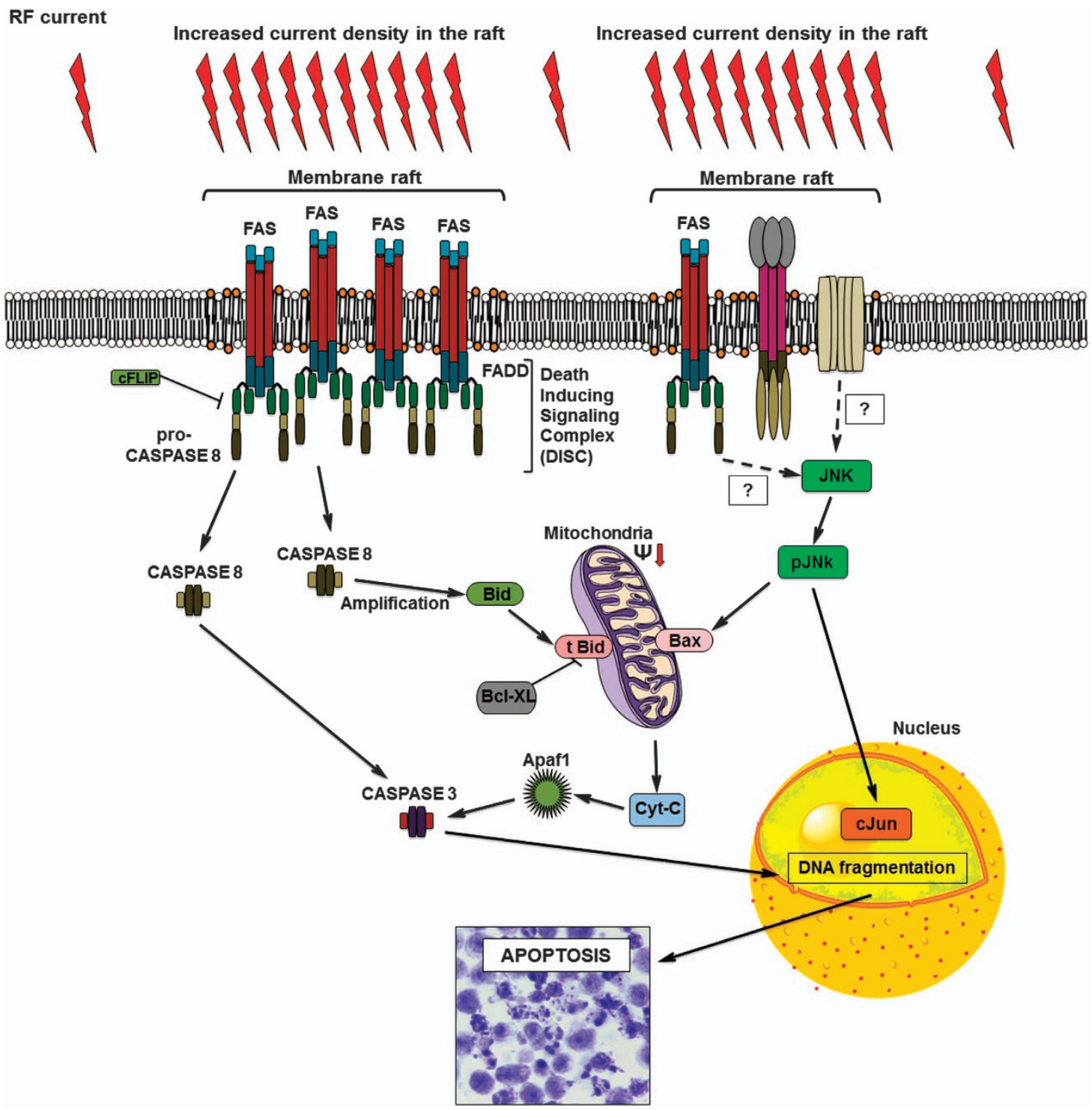

Figure 8. Schematic summary of the proposed molecular mechanism.

activation and significant loss of MMP, with increased $\left[\mathrm{Ca}^{2+}\right]_{\mathrm{i}}$, release. The activation of the extrinsic and intrinsic apoptotic signalling pathway resulted massive apoptotic cell death in mEHTtreated cells.

In this study, we proposed a novel mechanism for the biophysical manipulation of the membrane raft microdomain of the cancer cell using properly applied mEHT treatment. The specific RF energy absorption of the membrane raft results in distinct, inhomogenous energy distribution on the cell membrane causing localised heat stress, which activates cell death-related signalling pathways in $\mathrm{mEHT}$ treatment but not in conventional WHT treatment.

\section{MATERIALS AND METHODS}

Cell culture

U937, a human myelomonocytic lymphoma cell line from Human Sciences Research Resource Bank (Japan Human Sciences Foundation, Tokyo, Japan) was used for the experiments. The cells were grown in RPMI 1640 culture medium supplemented with $10 \%$ heat-inactivated foetal bovine serum at $37^{\circ} \mathrm{C}$ in humidified air with $5 \% \mathrm{CO}_{2}$. Cells were sub-cultured every second day, and were used for the experiments in their log phase. Cells were treated in $10^{6}$ cells $/ \mathrm{ml}$ density at a total volume of $8 \mathrm{ml}$.

\section{Treatment processes}

Here, $8 \mathrm{ml}$ U937 cell suspension was used in both the treatment objects. In the $\mathrm{mEHT}$ treatment process, the suspension was pipetted into a coverslipbottomed slide-flask (Nunc Lab-Tek II Chambered Coverglass, Thermo Fisher Scientific, Inc., Waltham, MA, USA) and placed into a special customdesigned platinum electrode applicator. (See the Supplementary material for details.) The active RF-electrode pure platinum (99.9\%) was used to minimise electrode by-products. The active electrode was immersed in the cell suspension. The effective surface of this platinum electrode was $10 \mathrm{~mm} \times 45 \mathrm{~mm}$. The AM modulated $13.56 \mathrm{MHz}$ RF source (LabEhy100, Oncotherm Ltd., Troisdorf, Germany) was connected to the applicator via a precise impedance matching unit. The complete heating-time was $30 \mathrm{~min}$.

In case of conventional WHT, $8 \mathrm{ml}$ cell suspension was filled in a $15 \mathrm{ml}$ centrifuge tube and then placed into a thermoregulated water bath (Thermo Minder SD Mini, Taitek Corp., Tokyo, Japan) continuously measuring the temperature profile during the treatment. The complete heating-time was well fit to $\mathrm{mEHT}, 30 \mathrm{~min}$ each. See Supplementary Figure 1 for the detailed experimental setup.

The heating dynamics and the treatment time at maximum temperature were the same in all treatments. After the treatments, cell suspensions 
were placed back into $10 \mathrm{~cm}$ plastic Petri dishes (BioBik, Ina-Optika Co. Ltd., Osaka, Japan) and incubated for $24 \mathrm{~h}$. All experiments were performed in triplicate.

\section{Temperature measurement during the heat treatments}

The temperature change of the cell suspension during the treatments was carried out by a four channel fluoroptic temperature measurement system (Luxtron m3300 Biomedical Lab Kit, Lumasense Technologies, Santa Clara, (A, USA). The temperature measurement probe is $0.5 \mathrm{~mm}$ in diameter and is an optical fibre, which is totally insensitive for the electromagnetic field. Probes 1 and 2 were used to monitor the temperature changes in the case of conventional heating, and probes 3 and 4 were used to measure the temperature profile of the $\mathrm{mEHT}$ treatment. The probes were precisely positioned to the inner surface of the slide-flask as well as to the lowest point in the centrifuge tube. The measured temperature parameters were recorded real-time (1 sampling per second) in a PC. A representative temperature measurement graph can be seen in the Supplementary Figure 2.

\section{Morphological detection of apoptosis}

To identify the morphological changes of the apoptotic cells after mEHT and conventional heat treatments, the cells were examined by Giemsa staining.

Cells were collected after $3 \mathrm{~h}$ of incubation at $37^{\circ} \mathrm{C}$, washed with PBS and collected by centrifugation. Then, the cells were fixed with methanol and acetic acid (3:1) for $24 \mathrm{~h}$ and spread onto glass slides. After drying, staining was performed with $5 \%$ Giemsa solution $(\mathrm{pH} \mathrm{6.8)}$ for 20 min, then washed with tap water. The cell samples on the slides were covered with a coverslip using Eukitt (O. Kindler GmbH \& Co., Freiburg, Germany). Cells were imaged using a conventional bright field microscope (Olympus BX61 Olympus Corp., Tokyo, Japan) equipped with a standard microscope camera (Olympus DP70, Olympus Corp., Tokyo, Japan).

\section{Detection of apoptosis using Annexin V-FITC/PI staining}

To quantitatively investigate the different heat treatment-induced early apoptosis and secondary necrosis, phosphatidylserine externalisation of apoptosis was determined by analysis of $\mathrm{PI}$ and fluorescein isothiocyanatelabelled Annexin V (Immunotech, Marseille, France) using Flow cytometry (Epics XL, Beckman-Coulter, Miami, Florida, USA) ${ }^{73}$ according to the instructions of the manufacturer. Briefly, followed by RF and conventional heat treatment, cells were collected after $3 \mathrm{~h}$ of $37^{\circ} \mathrm{C}$ incubation, washed with cold PBS at $4{ }^{\circ} \mathrm{C}$ and centrifuged at 1200 r.p.m. for $3 \mathrm{~min}$. The resulting pellet was mixed with binding buffer of the Annexin V-FITC kit. FITClabelled Annexin V $(5 \mu \mathrm{l})$ and PI $(5 \mu \mathrm{l})$ were added to the $490 \mu \mathrm{l}$ suspension and mixed gently. After incubation at $4{ }^{\circ} \mathrm{C}$ for $20 \mathrm{~min}$ in the dark, the cells were analysed by flow cytometry.

\section{DNA fragmentation assay}

For the detection of apoptosis, the percentage of DNA fragmentation was assessed until $3 \mathrm{~h}$ post-treatment using the method of Sellins and Cohen, ${ }^{74}$ with minor modifications. Briefly, $\sim 3 \times 10^{6}$ cells were lysed using $200 \mu \mathrm{l}$ of lysis buffer (10 mM Tris, $1 \mathrm{mM}$ EDTA and $0.2 \%$ Triton X-100, pH 7.5) and centrifuged at $13000 \times g$ for $10 \mathrm{~min}$. Subsequently, each DNA sample in the supernatant and the resulting pellet was precipitated in the $25 \%$ trichloroacetic acid at $4{ }^{\circ} \mathrm{C}$ overnight and quantified using a diphenylamine reagent after hydrolysis in $5 \%$ trichloroacetic acid at $90^{\circ} \mathrm{C}$ for $20 \mathrm{~min}$. The percentage of fragmented DNA in each sample was calculated as the amount of DNA in the supernatant divided by total DNA for that sample (supernatant plus pellet).

\section{Measurement of MMP}

After $3 \mathrm{~h}$ of incubation post-treatment at $37^{\circ} \mathrm{C}$, cells were harvested and stained with $10 \mathrm{nM}$ tetramethylrhodamine methyl ester (Molecular Probes, Eugene, OR, USA) for $15 \mathrm{~min}$ at $37^{\circ} \mathrm{C}$ in $1 \mathrm{ml}$ of PBS, followed by the immediate flow cytometry of red TMRM fluorescence (excitation at 488 $\mathrm{nm}$; emission at $575 \mathrm{~nm}$ )

Measurement of $\left[\mathrm{Ca}^{2+}\right]_{\mathrm{i}}$

To assess the effects of combined treatment on intracellular calcium homeostasis, intracellular free $\left[\mathrm{Ca}^{2+}\right]_{i}$ was measured using calcium probe
Fluo-3/AM (Dojindo Laboratories Co., Ltd., Kumamoto, Japan). After $3 \mathrm{~h}$ of post-treatment incubation at $37^{\circ} \mathrm{C}$, the cells were collected and then loaded with $5 \mu \mathrm{M}$ Fluo-3/AM for $30 \mathrm{~min}$ at $37^{\circ} \mathrm{C}$. Excess Fluo-3/AM was removed by washing three times with PBS. The fluorescence intensity of free $\left[\mathrm{Ca}^{2+}\right] \mathrm{i}$ levels was measured by flow cytometry.

\section{Microarray and computational gene expression analyses}

Gene expression was analysed using a GeneChip system with a Human Genome U133-plus 2.0 array, which was spotted with $\sim 54000$ probe sets (Affymetrix Inc., Santa Clara, CA, USA). Samples for array hybridisation were prepared as described in the Affymetrix GeneChip Expression Technical Manual (Affymetrix Inc.). The scanned arrays were analysed using the GeneChip Analysis Suite Software (Affymetrix Inc.). The obtained hybridisation intensity data were analysed using the GeneSpring analysis software (Silicon Genetics, Redwood City, CA, USA) to extract the significant genes. To examine gene ontology, including the biological processes, cellular components, molecular functions, and gene networks, the obtained data were analysed using the Ingenuity Pathways Analysis tools (Ingenuity Systems Inc.), a web-delivered application that enables the identification, visualisation, and exploration of molecular interaction networks in geneexpression data.

\section{Western blot analysis}

The cells were collected and washed with cold PBS. Cells were lysed at a density of $2.0 \times 10^{6}$ cells $/ 100 \mu$ l of RIPA buffer $(50 \mathrm{mM}$ Tris- $\mathrm{HCl}, 150 \mathrm{mM}$ $\mathrm{NaCl}, 1 \%$ Nonidet P-40 (v/v), $1 \%$ sodium deoxycholate, $0.05 \%$ SDS, $1 \mu \mathrm{g}$ of each aprotinin, pepstatin and leupeptin and $1 \mathrm{~mm}$ phenylmethyl sulphonyl fluoride) for $20 \mathrm{~min}$. Following brief sonification, the lysates were centrifuged at $12000 \times g$ for $10 \mathrm{~min}$ at $4{ }^{\circ} \mathrm{C}$, and the protein content in the supernatant was measured using the Bio-Rad protein assay kit (BioRad, Hercules, CA, USA). Protein lysates were denatured at $96^{\circ} \mathrm{C}$ for $5 \mathrm{~min}$, after mixing with SDS-loading buffers, applied on an SDS-PAGE gel (Daiichi Pure Chemicals Co., Ltd, Tokyo, Japan) for electrophoresis, and transferred to a nitrocellulose membrane (Amersham Biosciences, Buchinghamshire, UK). Western blot analysis was performed to detect Caspase-3, cleaved caspase-8, Bid, Bax, Bcl-2, Fas, JNK, P-JNK, ERK, P-ERK, and $\beta$-actin expression using specific polyclonal antibodies. Blots were then probed with either secondary horseradish peroxide-conjugated anti-rabbit or antimouse IgG antibodies obtained from Cell Signalling. Band signals were visualised on a luminescent image analyser (LAS 4000, Fujifilm Co., Tokyo, Japan) using chemiluminescence ECL detection reagents (Amersham Biosciences). Because of the weak visibility of the t-Bid signal, band density was quantified in this case by Image Studio software version 4 (LI-COR Biosciences, Lincoln, NE, USA), and the relative amounts of proteins associated with specific antibodies were normalised according to the intensities of $\beta$-actin.

\section{Statistical analysis}

The values are expressed as the means $\pm S D$. Statistical significance differences were evaluated using the Student's $t$-test. Values of $P<0.05$ were considered to be significant. All experiments were performed at least in triplicate.

\section{ACKNOWLEDGEMENTS}

This work was in part supported by the Grant-in-Aid for Scientific Research (B) (No.15H04904), the Japan Society for the Promotion of Science.

\section{AUTHOR CONTRIBUTIONS}

GA and MUR contributed equally to this work. GA, MUR and TK designed the study. GA, MUR and YT performed the experiments. All the authors discussed the data. GA and MUR wrote the paper with input from all the authors.

\section{COMPETING INTERESTS}

The authors declare no conflict of interest. 


\section{REFERENCES}

1 Hager ED, Dziambor H, Höhmann D, Gallenbeck D, Stephan M et al. Deep hyperthermia with radiofrequencies in patients with liver metastases from colorectal cancer. Anticancer Res 1999; 19: 3403-3408.

2 Wismeth C, Dudel C, Pascher C, Ramm P, Pietsch T et al. Transcranial electrohyperthermia combined with alkylating chemotherapy in patients with relapsed high-grade gliomas: phase I clinical results. J Neurooncol 2010; 98: 395-405.

3 Lee D, Haam YSJ, Kim TH, Lim JY, Eun Jung K, Na Young K. Oncothermia with chemotherapy in patients with small-cell lung cancer. Conf Pap Med 2013; 2013: $1-7$.

4 Gadaleta-Caldarola G, Infusino S, Galise I, Ranieri G, Vinciarelli G et al. Sorafenib and locoregional deep electro-hyperthermia in advanced hepatocellular carcinoma: a phase II study. Oncol Lett 2014; 8: 1783-1787.

5 Szasz O, Szasz A. Oncothermia-nano-heating paradigm. J Cancer Sci Ther 2014; 6: 117-121.

6 Andocs G, Szasz O, Szasz A. Oncothermia treatment of cancer: from the laboratory to clinic. Electromagn Biol Med 2009; 28: 148-165.

7 Cha J, Jeon TW, Lee CG, Oh ST, Yang HB, Lee YH et al. Electro-hyperthermia inhibits glioma tumorigenicity through the induction of E2F1-mediated apoptosis. Int J Hyperthermia 2015; 14: 1-9.

8 Meggyeshazi N, Andocs G, Balogh L, Balla P, Kiszner G, Teleki I et al. DNA fragmentation and caspase-independent programmed cell death by modulated electrohyperthermia. Strahlenther Onkol 2014; 190: 815-822.

9 Andocs G, Meggyeshazi N, Balogh L, Spisak S, Maros ME, Balla P et al. Up-regulation of heat shock proteins and the promotion of damage-associated molecular pattern signals in a colorectal cancer model by modulated electrohyperthermia. Cell Stress Chaperones 2015; 20: 37-46.

10 Qin W, Akutsu Y, Andocs G, Sugnami A, Hu X, Yusup G et al. Modulated electrohyperthermia enhances dendritic cell therapy through an abscopal effect in mice. Oncol Rep 2014; 2014: 3500.

11 Tsang YW, Chi MS, Wang YS, Andocs G, Li WT, Chi KH et al. Improving immunological tumour microenvironment using electro-hyperthermia followed by dendritic cell immunotherapy. BMC Cancer 2015; 15: 708.

12 Andocs G, Renner H, Balogh L, Fonyad L, Jakab C, Szasz A. Strong synergy of heat and modulated electromagnetic field in tumour cell killing. Strahlenther Onkol Organ Dtsch Rontgengesellschaft 2009; 185: 120-126.

13 Velizarov S, Raskmark P, Kwee S. The effects of radiofrequency fields on cell proliferation are non-thermal. Bioelectrochem Bioenerg. 1999; 48: 177-180.

14 de Pomerai D, Daniells C, David H, Allan J, Duce I, Mutwakil M et al. Non-thermal heat-shock response to microwaves. Nature 2000; 405: 417-418.

15 Blank M, Goodman R. A mechanism for stimulation of biosynthesis by electromagnetic fields: charge transfer in DNA and base pair separation. J Cell Physiol 2008; 214: 20-26.

16 Dawe AS, Smith B, Thomas DW, Greedy S, Vasic N, Gregory A et al. A small temperature rise may contribute towards the apparent induction by microwaves of heat-shock gene expression in the nematode Caenorhabditis elegans. Bioelectromagnetics 2006; 27: 88-97.

17 Foster KR. Thermal and nonthermal mechanisms of interaction of radio-frequency energy with biological systems. IEEE Trans Plasma Sci 2000; 28: 15-23.

18 Lebovitz RM. Significance of microthermal effects derived from low level UHF-microwave irradiation of the head: indirect caloric vestibular stimulation. J Theor Biol 1973; 41: 209-221.

19 Liu LM, Cleary SF. Absorbed energy distribution from radio frequency electromagnetic radiation in a mammalian cell model: effect of membrane-bound water. Bioelectromagnetics 1995; 16: 160-171.

20 Vorst AV. Microthermal and isothermal biological effects under microwave exposure. Microwave Review (Mikrotalasna revija) 2005; 11: 2-12.

21 Sheppard AR, Balzano Q. Quantitative evaluations of mechanisms of radiofrequency interactions with biological molecules and processes. Health Phys 2008; 95: $365-396$.

22 Singer SJ, Nicolson GL. The fluid mosaic model of the structure of cell membranes. Science 1972; 175: 720-731.

23 Lingwood D, Simons K. Lipid rafts as a membrane-organising principle. Science 2010; 327, 46-50.

24 Diaz-Rohrer BB, Levental KR, Simons K, Levental I. Membrane raft association is a determinant of plasma membrane localisation. Proc Natl Acad Sci USA 2014; 111: 8500-8505.

25 Pike LJ. Rafts defined: a report on the keystone symposium on lipid rafts and cell function. J Lipid Res 2006; 47: 1597-1598.

26 Pike LJ. Lipid rafts—bringing order to chaos. J Lipid Res 2003; 44: 655-667.

27 Szasz A. Electromagnetic effects in nanoscale range. In: Shimizu T, Kondo T (eds). Cellular Response to Physical Stress and Therapeutic Application, Ch 4. Nova Science Publisher: New York, NY, USA, 2013, pp 55-81.

28 Szasz O, Szasz A. Oncothermia-nano-heating paradigm. J Cancer Sci Ther 2014; 6: 117-121.
29 Andocs G, Rehman MU, Zhao QL, Papp E, Kondo T et al. Nanoheating without artificial nanoparticles part II. Experimental support of the nanoheating concept of the modulated electro-hyperthermia method, using U937 cell suspension model. Biol Med (Aligarh) 2015; 7: 247.

30 Vincze Gy, Szigeti Gy, Andocs G, Szasz A. Nanoheating without artificial nanoparticles. Biol Med (Aligarh) 2015; 7: 249.

31 Kotnik T, Miklavcic D. Theoretical evaluation of the distributed power dissipation in biological cells exposed to electric fields. Bioelectromagnetics 2000; 394 385-394.

32 Adey WR. Biological effects of electromagnetic fields. J Cell Biochem 1993; 51 410-416.

33 Polk C, Postow E. Handbook of Biological Effects of Electromagnetic Fields. CRC Press: Boca Raton, FL, USA, 1996.

34 Papp E, Vancsik T, Kiss E, Szasz A. Membrane raft absorption in the modulated electro-hyperthermia (mEHT). J Cancer Res Ther (in review).

35 Hirano H, Tabuchi Y, Kondo T, Zhao Q-L, Ogawa R, Cui Z-G et al. Analysis of gene expression in apoptosis in human lymphoma U937 cells induced by heat shock and the effects of a-phenyl N-tertbutylnitrone (PBN) and its derivatives. Apoptosis 2005; 10: 331-340.

36 Tabuchi Y, Takasaki I, Wada S, Zhao QL, Hori T, Kondo T et al. Genes and genetic networks responsive to mild hyperthermia in human lymphoma U937 cells. Int $\mathrm{J}$ Hyperthermia 2008; 24: 613-622.

37 Wada S, Tabuchi Y, Kondo T, Cui ZG, Zhao QL, Ogawa R et al. Gene expression in enhanced apoptosis of human lymphoma U937 cells treated with the combination of different free radical generators and hyperthermia. Free Radic Res 2007; 41 73-81.

38 Kameda K, Kondo T, Tanabe K, Zhao QL, Seto $\mathrm{H}$. The role of intracellular $\mathrm{Ca}^{2+}$ in apoptosis induced by hyperthermia and its enhancement by verapamil in U937 cells. Int J Radiat Oncol Biol Phys 2001; 49: 1369-1379.

39 Furusawa Y, Tabuchi Y, Wada S, Takasaki I, Ohtsuka K, Kondo T. Identification of biological functions and gene networks regulated by heat stress in U937 human lymphoma cells. Int J Mol Med 2011; 28: 143-151.

40 Davis RJ. Signal transduction by the JNK group of MAP kinases. Cell 2000; 103, pp 239-252.

41 Wu Y-T, Zhang S, Kim Y-S, Tan H-L, Whiteman M, Ong C-N et al. Signalling pathways from membrane lipid rafts to JNK1 activation in reactive nitrogen species-induced non-apoptotic cell death. Cell Death Differ 2008; 15: 386-397.

42 Gajate C, Del Canto-Janez E, Acuna AU, Amat-Guerri F, Geijo E, Santos-Beneit AM. Intracellular triggering of Fas aggregation and recruitment of apoptotic molecules into Fas-enriched rafts in selective tumour cell apoptosis. J Exp Med 2004; 200: 353-365.

43 Lanneau D, Brunet M, Frisan E, Solary E, Fontenay M, Garrido C. Heat shock proteins: essential proteins for apoptosis regulation. J Cell Mol Med 2008; 12: 743-761.

44 Mosser DD, Morimoto RI. Molecular chaperones and the stress of oncogenesis. Oncogene 2004; 23: 2907-2918.

45 Wajant H. Principles and mechanisms of CD95 activation. Biol Chem 2014; 395 1401-1416.

46 Fouqu'e A, Debure L, Legembre P. The CD95/CD95L signalling pathway: a role in carcinogenesis. Biochim Biophys Acta 2014; 1846: 130-141.

47 Hueber AO. Role of membrane microdomain rafts in TNFR-mediated signal transduction. Cell Death Differ 2003; 10: 7-9.

48 Scheel-Toellner D, Wang K, Singh R, Majeed S, Raza K, Curnow SJ et al. The deathinducing signalling complex is recruited to lipid rafts in Fas-induced apoptosis. Biochem Biophys Res Commun 2002; 297: 876-879.

49 Eramo A, Sargiacomo M, Ricci-Vitiani L, Todaro M, Stassi G, Messina CG et al. CD95 death-inducing signalling complex formation and internalization occur in lipid rafts of type land type II cells. Eur J Immunol 2004; 34: 1930-1940.

50 Mollinedo F, Gajate C. Lipid rafts and clusters of apoptotic signalling moleculeenriched rafts in cancer therapy. Future Oncol 2010; 6: 811-821.

51 Gajate C, Mollinedo F. Lipid rafts and Fas/CD95 signalling in cancer chemotherapy. Recent Pat Anticancer Drug Discov 2011; 6: 274-283.

52 Gajate C, Mollinedo F. Lipid rafts, endoplasmic reticulum and mitochondria in the anti-tumour action of the alkylphospholipid analogue edelfosine. Anticancer Agents Med Chem 2014; 14: 509-527.

53 Mollinedo F, Gajate C. Fas/CD95 death receptor and lipid rafts: new targets for apoptosis-directed cancer therapy. Drug Resist Updat 2006; 9: 51-73.

54 Mollinedo F, Gajate C. Lipid rafts, death receptors and CASMERs: new insights for cancer therapy. Future Oncol 2010; 6: 491-494.

55 Mollinedo F, Gajate C. Lipid rafts as major platforms for signalling regulation in cancer. Adv Biol Regul 2015; 57: 130-146.

56 Gajate C, Mollinedo F. Edelfosine and perifosine induce selective apoptosis in multiple myeloma by recruitment of death receptors and downstream signalling molecules into lipid rafts. Blood 2007; 109: 711-719. 
57 Lacour S, Hammann A, Grazide S, Lagadic-Gossmann D, Athias A, Sergent O et al. Cisplatin-induced CD95 redistribution into membrane lipid rafts of HT29 human colon cancer cells. Cancer Res 2004; 64: 3593-3598.

58 Nourissat P, Travert M, Chevanne M, Tekpli X, Rebillard A, Le Moigne-Müller G et al. Ethanol induces oxidative stress in primary rat hepatocytes through the early involvement of lipid raft clustering. Hepatology 2008; 47: 59-70.

59 Delmas D, Rebe C, Micheau O, Athias A, Gambert P, Grazide S et al. Redistribution of CD95, DR4 and DR5 in rafts accounts for the synergistic toxicity of resveratrol and death receptor ligands in colon carcinoma cells. Oncogene 2004; 23: 8979-8986.

60 Tekpli X, Holme JA, Sergent O, Lagadic-Gossmann D. Role for membrane remodelling in cell death: implication for health and disease. Toxicology 2013; 304: 141-157.

61 Nagarsekar A, Greenberg RS, Shah NG, Singh IS, Hasday JD. Febrile-range hyperthermia accelerates caspase-dependent apoptosis in human neutrophils. J Immunol 2008; 181: 2636-2643.

62 Balogh G, Maulucci G, Gombos I, Horvath I, Torok Z et al. Heat stress causes spatially-distinct membrane re-modelling in K562 leukaemia cells. PLoS One 2011; 6: e21182.

63 Yan G, Huang J, Jarbadan NR, Jiang Y, Cheng H. Sequestration of NF-kappaB signalling complexes in lipid rafts contributes to repression of NF-kappaB in T lymphocytes under hyperthermia stress. J Biol Chem 2008; 283: 12489-12500.

64 Csoboz B, Balogh G, Kusza E, Gombos I, Horvath I, Vigh L et al. Membrane fluidity matters: Hyperthermia from the aspects of lipids and membranes. Int $J$ Hyperthermia 2013; 29: 491-499.

65 Moulin M, Carpentier S, Levade T, Arrigo AP. Potential roles of membrane fluidity and ceramide in hyperthermia and alcohol stimulation of TRAIL apoptosis. Apoptosis 2007; 12: 1703-1720.

66 Kischkel FC, Hellbardt S, Behrmann I, Germer M, Pawlita M, Krammer PH et al. Cytotoxicity-dependent APO-1 (Fas/CD95)-associated proteins form a deathinducing signalling complex (DISC) with the receptor. EMBO J 1995; 14: 5579-5588.
67 Ashkenazi A, Dixit VM. Death receptors: signalling and modulation. Science 1998; 281: 1305-1308.

68 Salvesen GS, Dixit VM. Caspase activation: the induced-proximity model. Proc Natl Acad Sci USA 1999; 96: 10964-10967.

$69 \mathrm{Li} \mathrm{H}, \mathrm{Zhu} \mathrm{H}, \mathrm{Xu} \mathrm{CJ}$, Yuan J. Cleavage of BID by caspase 8 mediates the mitochondrial damage in the Fas pathway of apoptosis. Cell 1998; 94: 491-501.

70 Luo X, Budihardjo I, Zou H, Slaughter C, Wang X. Bid, a Bcl2 interacting protein, mediates cytochrome $\mathrm{c}$ release from mitochondria in response to activation of cell surface death receptors. Cell 1998; 94: 481-490.

71 Strasser A, Newton K. FADD/MORT1, a signal transducer that can promote cell death or cell growth. Int J Biochem Cell Biol 1999; 31: 533-537.

72 Yin XM. Signal transduction mediated by Bid, a pro-death Bcl-2 family protein, connects the death receptor and mitochondria apoptosis pathways. Cell Res 2000; 10: 161-167.

73 Cui ZG, Piao JL, Rehman MU, Ogawa R, Li P, Zhao QL et al. Molecular mechanisms of hyperthermia-induced apoptosis enhanced by withaferin A. Eur J Pharmacol 2014; 723: 99-107.

74 Sellins KS, Cohen JJ. Gene induction by gamma irradiation leads to DNA fragmentation in lymphocytes. J Immunol 1987; 139: 3199-3206.

\section{(c) (i)}

This work is licensed under a Creative Commons Attribution 4.0 International License. The images or other third party material in this article are included in the article's Creative Commons license, unless indicated otherwise in the credit line; if the material is not included under the Creative Commons license, users will need to obtain permission from the license holder to reproduce the material. To view a copy of this license, visit http://creativecommons.org/licenses/ by/4.0/

(c) The Author(s) 2016

Supplemental Information accompanies the paper on the Cell Death Discovery website (http://www.nature.com/cddiscovery) 